\title{
ANALISA PERBANDINGAN KETELITIAN PENENTUAN POSISI DENGAN GPS RTK-NTRIP DENGAN BASE GPS CORS BIG DARI BERBAGAI MACAM MOBILE PROVIDER DIDASARKAN PADA PERGESERAN LINEAR
}

\section{(Studi Kasus : Surabaya)}

\author{
Atika Sari, Khomsin \\ Jurusan Teknik Geomatika, FTSP, ITS-Sukolilo, Surabaya, $60111^{12}$ \\ Email : khomsin95@yahoo.com²
}

\begin{abstract}
Abstrak
Penentuan posisi dalam pemetaan menggunakan penginderaan jauh dan foto udara memerlukan pengamatan GPS geodetik sebagai titik kontrol yang memilki ketelitian tinggi. Sistem koreksi data penentuan posisinya diperoleh dari transmisi data dari stasiun base ke receiver. Dalam perkembangan sekarang ini metode pengukuran RTK telah menggunakan metode NTRIP (Networked Transport of RTCM via Internet Protocol) sebagai metode transmisi koreksi data dengan menggunakan intenet sehingga pengukuran tersebut masih bisa dilakukan dengan jarak yang lebih jauh dari base-nya. Pada metode NTRIP ini menggunakan metode pengiriman koreksi data GNSS melalui jaringan internet. Pengembangan sistem dengan fasilitas akses internet mobile melalui general packet radio service (GPRS) dan global system for mobile (GSM), menyediakan metode cepat dan handal untuk mendistribusikan baris data GPS atau koreksi diferensial real-time (DGPS / RTK) ke penerima GPS di daerah manapun yang berada di bawah jangkauan jaringan telepon seluler. Sehingga untuk mengetahui provider yang sesuai digunakan dalam wilayah surabaya dalam menggunakan metode RTK NTRIP maka dilakukanlah penelitian ini. Dari hasil pengamatan dari pengukuran dengan menggunakan metode RTK-NTRIP dengan base GPS CORS BIG didapat nilai ratarata dari masing-masing provider sekitar $<4 \mathrm{~m}$.
\end{abstract}

Kata Kunci : GPS, CORS, NTRIP, RTK, Provider

\section{PENDAHULUAN}

\section{Latar Belakang}

Penetuan posisi dalam pemetaan menggunakan penginderaan jauh dan foto udara memerlukan pengamatan GPS geodetik sebagai titik kontrol yang memiliki ketelitian tinggi. Sistem koreksi data penentuan posisinya diperoleh dari transmisi data dari stasiun base ke receiver. Dalam perkembangan sekarang ini metode pengukuran RTK telah menggunakan metode NTRIP sebagai metode transmisi koreksi data dengan menggunakan intenet sehingga pengukuran tersebut masih bisa dilakukan dengan jarak yang lebih jauh dari base-nya.

Dengan meningkatnya bandwith yang tersedia dari internet, para peneliti mulai mengembangkan penggunaan internet sebagai alternatif transmisi data pengamatan GPS. Sehingga memungkinkan untuk streaming data koreksi DGPS atau RTK untuk penentuan posisi dan navigasi yang tepat. Teknologi baru ini diumumkan pada akhir tahun
2004 dengan nama Networked Transport of RTCM via Internet Protocol (NTRIP) yang dikembangkan oleh Federal Agency for Cartography and Geodesy, Germany (BKG). Dan dengan itu maka dibuthkan penggunaan GSM untuk menunjang transmisi data dari base ke rover dengan menggunakan metode RTK-NTRIP. Di Indonesia sendiri mempunyai beberapa GSM yang yang telah dipercaya sekaligus menawarkan layanan internet yang memadai diantaranya adalah Telkomsel, Indosat, XI, Axis dan Three (3).

CORS (Continuously Operating Reference Station) biasa disebut juga stasiun referensi permanen adalah sistem yang terdiri dari receiver GPS dan antena GPS yang diatur secara baik pada lokasi yang aman dengan ketersediaan sumber energi yang handal serta dengan perangkat TIK yang dapat melayani layanan koreksi [1]

Teknik baru menggunakan internet untuk streaming dan sharing DGPS untuk menyediakan posisi yang presisi dan navigasi yang yang telah 
dikenal dengan nama NTRIP. NTRIP adalah metode dalam pengiriman koreksi data GNSS (Global Navigation Satellite System) melalui jaringan internet. NTRIP "jaringan" terdiri dari NtripClient (pennguna), NtripServer (stasiun referensi), dan NtripCaster (pusat kendali).

Pengembangan sistem dengan fasilitas akses internet mobile melalui general packet radio service (GPRS) dan global system for mobile (GSM), menyediakan metode cepat dan handal untuk mendistribusikan baris data GPS atau koreksi diferensial real-time (DGPS / RTK) ke penerima GPS di daerah manapun yang berada di bawah jangkauan jaringan telepon seluler. Koneksi internet tergantung dari pelayanan mobile provider IP network. Di Indonesia terdapat beberapa mobile provider IP network yang diantaranya adalah Indosat, Telkomsel, XL, 3 dan Axis. Penelitian sebelumnya pernah dilakukan di daerah Sleman Bantul dan didapat bahwa untuk daerah tersebut mobile provider $\mathrm{XL}$ yang dinyatakan paling bagus, dan untuk penelitian di daerah Jakarta didapat bahwa Telkomsel yang paling bagus, maka untuk daerah Surabaya perlu dilakukan penelitian untuk mengetahui mobile provider yang sesuai digunakan untuk melakukan pengukuran GPS dengan metode RTK - NTRIP.

\section{Perumusan Masalah}

Dari latar belakang di atas, maka permasalahan yang timbul adalah seberapa besar tingkat ketelitian dan kecepatan akses internet untuk mencapai nilai fix pengukuran posisi dengan menggunakan GPS dari berbagai provider dengan metode RTK-NTRIP.

\section{METODOLOGI PENELITIAN Lokasi Penelitian}

Lokasi penelitian Tugas Akhir ini mengambil daerah studi di Kota Surabaya.
Tabel 1 Lokasi Penelitian

\begin{tabular}{cccc}
\hline No & Lintang & Bujur & Lokasi \\
\hline \hline 1 & $7^{\circ} 16^{\prime} 50^{\prime \prime}$ & $112^{\circ} 47^{\prime} 32^{\prime \prime}$ & ITS \\
2 & $7^{\circ} 20^{\prime} 07^{\prime \prime}$ & $112^{\circ} 42^{\prime} 57^{\prime \prime}$ & Masjid Al Akbar \\
3 & $7^{\circ} 19^{\prime} 41^{\prime \prime}$ & $112^{\circ} 43^{\prime} 53^{\prime \prime}$ & Taman Pelangi \\
4 & $7^{\circ} 19^{\prime} 34^{\prime \prime}$ & $112^{\circ} 43^{\prime} 06^{\prime \prime}$ & Kebon Sari \\
5 & $7^{\circ} 18^{\prime} 00^{\prime \prime}$ & $112^{\circ} 40^{\prime} 31^{\prime \prime}$ & UNESA Lidah \\
6 & $7^{\circ} 16^{\prime} 26^{\prime \prime}$ & $112^{\circ} 48^{\prime} 24^{\prime \prime}$ & PTC \\
7 & $7^{\circ} 17^{\prime} 07^{\prime \prime}$ & $112^{\circ} 40^{\prime} 33^{\prime \prime}$ & Lontar \\
8 & $7^{\circ} 12^{\prime} 33^{\prime \prime}$ & $112^{\circ} 44^{\prime} 04^{\prime \prime}$ & Perak \\
9 & $7^{\circ} 12^{\prime} 36^{\prime \prime}$ & $112^{\circ} 46^{\prime} 44^{\prime \prime}$ & Suramadu \\
10 & $7^{\circ} 14^{\prime} 03^{\prime \prime}$ & $112^{\circ} 46^{\prime} 59^{\prime \prime}$ & Bulak \\
& & & Lap. Skateboard \& \\
11 & $7^{\circ} 15^{\prime} 50^{\prime \prime}$ & $112^{\circ} 45^{\prime} 00^{\prime \prime}$ & BMX \\
12 & $7^{\circ} 15^{\prime} 36^{\prime \prime}$ & $112^{\circ} 44^{\prime} 49^{\prime \prime}$ & Balai Kota \\
13 & $7^{\circ} 17^{\prime} 29^{\prime \prime}$ & $112^{\circ} 44^{\prime} 23^{\prime \prime}$ & Taman Bungkul \\
15 & $7^{\circ} 19^{\prime} 28^{\prime \prime}$ & $112^{\circ} 47^{\prime} 41^{\prime \prime}$ & Rungkut \\
\hline & $7^{\circ} 17^{\prime} 24 "$ & $112^{\circ} 48^{\prime} 13^{\prime \prime}$ & Keputih \\
\hline
\end{tabular}

\section{Data dan Peralatan}

\section{Data}

Data yang dibutuhkan dalam penelitian Tugas Akhir ini antara lain :
a. Data koordinat titik hasil pengamatan dengan GPS metode static.
b. Data koordinat titik hasil pengamatan dengan GPS metode RTK-NTRIP dari berbagai provider.

\section{Peralatan}

Peralatan yang digunakan dalam penelitian ini adalah Personal Computer (PC) / Notebook, Microsoft Office 2007, Pengolahan data GPS, GPS ProMark 100/200, Mobile Provider, Base GPS CORS BIG.

\section{Tahapan Penelitian}

Diagram Alir proses Pengolahan Data pada penelitian ini ditunjukkan oleh Gambar 1. 


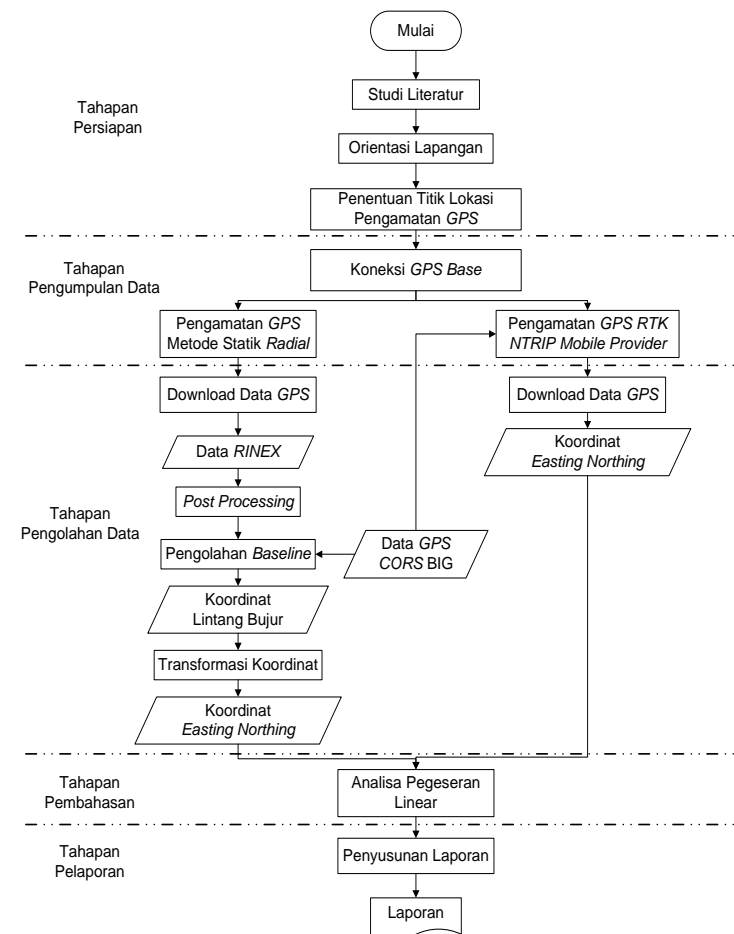

Gambar 1. Diagram Alir Tahapan Penelitian

Penjelasan dari diagram alir di atas adalah :

1. Tahapan Persiapan

Tahapan ini terdiri dari identifikasi dan perumusan masalah beserta penetapan tujuan penelitian, studi literatur yang berhubungan dengan pengukuran GPS dengan metode RTK - NTRIP dengan berbagai mobile provider IP network, dan orientasi lapangan serta penentuan lokasi titik.

2. Tahapan Pengumpulan Data

Pada tahapan ini adalah dilakukan pengambilan data secara langsung di lokasi penelitian. Pengumpulan data dilakukan dengan cara pengukuran GPS dengan metode RTK - NTRIP dengan masing - masing menggunakan mobile provider IP network yang berbeda pada tahap ini dilakukan pengukuran untuk mengetahui kecepatan masing - masing provider dalam mencapai nilai fix pengukuran dan apabila tidak bisa mencapai nilai fix pengukuran waktunya dibatasi sampai 15 menit dan data di record sesuai dengan nilainya. Pengambilan data suatu titik dilakukan dalam 3 kali yaitu pagi (jam 8-10), siang (12-16) dan malam hari (1922) untuk menentukan waktu pengukuran yang baik dalam pengukuran GPS dengan
RTK-NTRIP. Dan juga dilakukan pengukuran dengan menggunakan statik sebagai acuan nilai yang dianggap benar.

3. Tahapan Pembahasan

Pada tahapan ini dilakukan pengolahan data dengan software. Data yang telah diperoleh dari lapangan didownload dari server lalu diolah dengan software sehingga menghasilkan nilai koordinat titik fix. Dari hasil pengukuran tersebut juga dibandingkan dengan hasil pengukuran menggunakan metode statik sebagai acuan koordinatnya.

4. Tahapan Persiapan

Pada tahapan ini adalah untuk menganalisa perbandingan yang diperoleh dari hasil pengukuran dengan menggunakan berbagai mobile provider IP network. Dari hasil pengukuran yang diperoleh perbandingan ketelitian serta dari kecepatan dalam pengamatan mencapai nilai fix. Pada tahap ini juga dilakukan analisa pergeseran linear. Maka dari hasil analisa itu dapat ditarik kesimpulan dari hasil pengukuran dan analisa dari penelitian tersebut.

5. Tahapan Akhir

Pada tahapan ini dilakukan penyusunan dan penulisan laporan dari hasil yang didapat serta pelaporan hasil berupa perbandingan keakuratan dan ketelitian dari berbagai mobile provider IP network.

\section{HASIL DAN ANALISA}

Dari hasil pengamatan juga diperoleh nilai ratarata pergerseran linear dari masing-masing kartu dengan data statik sebagai acuannnya. Berikut data rata-rata pergeseran linear masing-masing provider :

$\begin{array}{ll}\text { Axis } & : 3,795 \mathrm{~m} \\ \text { Telkomsel } & : 3,272 \mathrm{~m} \\ \text { XI } & : 3,533 \mathrm{~m} \\ \text { Indosat } & : 3,462 \mathrm{~m} \\ \text { Three (3) } & : 3,288 \mathrm{~m}\end{array}$

Dammage (2006) melakukan penelitian tentang penggunaan metode NTRIP dengan menggunakan dual frekuensi di Thailand. Dengan menggunakan metode RTK NTRIP dan RTK dengan menggunakan komunukasi radio menghasilkan nilai akurasi sebesar $0,158 \mathrm{~m}$ dan $0,16 \mathrm{~m}$ dengan jarak baseline 5 - $30 \mathrm{~km}$. Selain itu, metode NTRIP dapat 
meningkatkan akurasi hasil pengamatan dengan berbagai fariasi jarak baseline antara base dan rover dibandingkan dengan menggunakan pengukuran GPS yang menggunakan gelombang radio.

Pada hasil diatas diperoleh bahwa nilai pergeseran linear dari masing-masing kartu sangat tinggi yaitu lebih $<4 \mathrm{~m}$ setara dengan penggunaan GPS Navigasi. Ada beberapa faktor yang menyebabkan tingginya nilai pergeseran linear tersebut diantaranya adalah :

a. Tidak stabilnya jaringan pada sistem base GPS CORS BIG

b. Jarak base dan rover yang tidak selalu sama dikarenakan keadaan sistem yang kurang stabil

c. Koneksi internet sendiri yang kurang stabil juga dimungkinkan sehingga data koreksi ada yang hilang sehingga data tidak sempurna

d. Disebabkan oleh faktor troposfer dan ionesfer

e. Pengukuran dengan menggunakan satu referensi satelit sehingga nilai koordinatnya hanya dikoreksi oleh satu stasiun saja.

Pada saat dilakukannya pengukuran base CORS sedang dalam keadaan kurang stabil sering putus pada waktu pengukuran ,sulitnya menghubungkan dengan server basenya sehingga apabila digunakan dalam pengukuran tersebut untuk mendapat nilai fix terkadang sangat sulit, sehingga dalam waktu 15menit belum mendapatkan nilai fix. Dan hal itu pula mempengaruhi nilai linearnya serta kecepatan dalam mencapai fix. Dalam GPS CORS BIG sendiri mempunyai 2 sistem yang ada untuk menghubungkan dengan server CORS BIG yaitu dengan base yang lain yang menggunakan server spider. Server Trimble pivot merupakan server milik trimble, sebenarnya server ini digunakan hampir semua jaringan CORS BIG sehingga apabila GPS CORS BIG dengan mountpoint multistation atau nearest dalam keadaan kurang baik atau sistemnya sedang tidak berjalan maka akan dihubungkan dengan base GPS CORS yang posisinya relatif tidak terlalu jauh namun kadang jaringan.Spider adalah sistem milik leica yang koneksinya lumayan cepat apabila mountpoint nearest/multistationnya yang terhubung dengan base terdekat layanan dan kondisi GPS CORS-nya bagus namun apabila kondisi GPS CORS-nya sedang bermasalah maka sistem akan menghubungkan base-nya. Dan dalam melakukan pengukuran dengan menggunakan GPS CORS BIG sebaiknya memantau aktivitas GPS CORS BIG sekitar daerah pengukuran apakah dalam keadaan baik dan siap digunakan hal ini untuk melakukan pengukuran secara lancar.

Berdasarkan hasil yang diperoleh pada penelitian ini diperoleh rata-rata nilai pergeseran linear adalah $>3$ meter. Dari hasil tersebut apabila digunakan sebagai GCP untuk citra satelit, maka masing-masing provider dengan menggunakan metode RTK-NTRIP dapat digunakan untuk GCP citra satelit resolusi sebagai berikut

Tabel 2. Tabel daftar citra dan resolusinya

\begin{tabular}{ccc}
\hline No & Citra Satelit & Resolusi Spasial $(\mathrm{m})$ \\
\hline \hline 1 & Landsat & $30 \times 30$ \\
2 & Spot & $10 \times 10$ \\
3 & NOAA & $1000 \times 1000$ \\
4 & Terra & $30 \times 30$ \\
5 & IRS & $6 \times 6$ \\
\hline
\end{tabular}

\section{PENUTUP}

Berdasarkan hasil penelitian di atas, dapat disimpulkan sebagai berikut :

1. Dari hasil pengukuran dengan menggunakan metode RTK-NTRIP dengan base CORS BIG didapat ketelitian rata-rata yang diperoleh dari masing - masing provider adalah untuk Axis 3,795 m, Telkomsel 3,273 m, XI 3,533 m, Indosat 3,462 $\mathrm{m}$ dan Three (3) 3,288 m.

2. Didasarkan pada nilai pergeseran linear maka yang bagus adalah provider Telkomsel.

\section{DAFTAR PUSTAKA}

Aditya, Arif dkk. 2014. Infrastructure of GNSS CORS in Indonesia. Kuala Lumpur : FIG Conggress 2014.

Anonim. RTCM Documentation Networked Transport of RTCM via Internet Protocol (Ntrip) Version 1.0.

BPN (Badan Pertanahan Nasional). 2011. On The Job Training Pengenalan CORS (Continously Operating Reference Station). Jakarta : Badan Pertanahan Nasional.

Dammalage, T.L dkk. 2006. Potential Accuracy and Practical Benefits of NTRIP Protocol over Conventional RTK and DGPS Observation 
Methods. Bangkok : 5th Annual International Conference Map Asia.

Lenz, Elmar. 2004. Networked Transport of RTCM via Internet Protocol (NTRIP) - Application and Benefit in Modern Surveying System. Athens : FIG Working Week 2004.

Sandi, Alisa Harlia dkk. 2012. Status Stasiun Continously Operating Reference Station (CORS) Badan Informasi Geospasial (BIG) 2012. Bogor : Pusat Jaring Kontrol Geodesi dan Geodinamika Badan Informasi Geospasial.

Sunantyo, T. Aris Dkk. 2010. Studi Penggunaan Metode RTK-NTRIP dengan Provider Mobile Internet Protocol Telkomsel, XL dan Indosat untuk Pengecekan Titik Dasar Teknik Orde-4 di Desa Banyuraden Gamping Sleman, DIY. Yogyakarta : Seminar Nasional GNSS-CORS Yogyakarta.

Schwieger, Volker. 2007. GNSS CORS Networks

Principles. San Jose : 6th FIG Regional Conference. 